\title{
ALOE VERA VS. SILVER SULFADIAZINE FOR TREATING SECOND-DEGREE BURN WOUNDS: EVIDENCE-BASED CASE REPORT
}

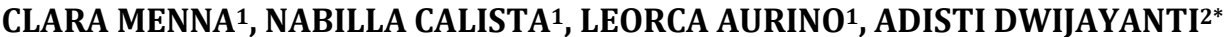

1Undergraduate Program, Faculty of Medicine, Universitas Indonesia, Jakarta, ${ }^{2}$ Department of Medical Pharmacy, Faculty of Medicine, Universitas Indonesia, Jakarta

Email: adisti.dwijayanti@ui.ac.id

Received: 15 Dec 2018, Revised and Accepted: 10 Mar 2019

\section{ABSTRACT}

Objective: Current treatment for second-degree burn wounds, including silver sulfadiazine (SSD) application, may cause side effects such as delayed and incomplete wound healing, leaving a scar. Traditional plants empirically used for burn wounds, such as Aloe vera, seem to be a promising option with good safety profiles.

Methods: We therefore compared Aloe vera to SSD for second-degree burn wounds based on a review of clinical trials obtained by an organized search through the Cochrane, PubMed, and DynaMed databases. Three randomized clinical trials studies were selected, two of which were critically appraised. The third study, with a different outcome assessment, was analyzed separately.

Results: Two studies showed that Aloe vera was more effective in treating second-degree burn wounds than SSD 1\% with an absolute risk reduction of 0.2 , relative risk reduction of $0.83-1.0$, and number needed to treat five patients. The Aloe vera group showed faster healing, earlier epithelialization, and earlier pain alleviation. The third study combined Aloe vera with other herbs, which showed better healing ability and restored skin hydration than those with SSD.

Conclusion: Each of the three articles stated that Aloe vera was more effective than SSD for treating second-degree burn wounds. Nevertheless, each of the studies lacked methodology and comprehensive data reporting.

Keywords: Aloe vera, Second-degree burn wounds, Silver sulfadiazine

(C) 2019 The Authors. Published by Innovare Academic Sciences Pvt Ltd. This is an open access article under the CC BY license (http://creativecommons. org/licenses/by/4. 0/) DOI: http://dx.doi.org/10.22159/ijap.2019.v11s6.33580

\section{INTRODUCTION}

Aloe vera has been used as a traditional medicine for centuries. Originating in Egypt, it is now found worldwide [1]. The main component of Aloe is water, which makes up $99.5 \%$ of the plant. The remaining $0.5 \%$ is solid materials that have been identified as 75 active compounds, including vitamins, enzymes, phenols, and organic acid [2]. Aloe vera is commonly used to reduce symptoms of gastroesophageal reflux and irritable bowel syndrome [3]. Over time, Aloe vera has been found to have anti-inflammatory, antimicrobial, antiviral, and antifungal properties [3-6]. In the general society, oral Aloe vera is used as a laxative, immunostimulant, and detoxing agent, whereas topical Aloe is used to prevent acne and dry skin and to treat burn wounds [3-5]. Preclinical trials of topical Aloe vera as burn treatment have been conducted in several in vivo studies in rats. Akhoondinasab et al. [7] studied 16 rats with second-degree burns that were divided into two groups: one treated with SSD and the other with Aloe vera, The results showed more visible healing in the Aloe vera group. This result encouraged scientists to perform clinical trials, although the controversy concerning the use of Aloe vera to treat skin injuries such as burns remains. To that point, Schmidt and Greenspoon [8] conducted a study whose results indicated that Aloe vera delayed wound healing.

According to Hermans [9], the most commonly used topical antibiotic for burn management is $1 \%$ silver sulfadiazine (SSD) cream. According to the burn management guideline from the plastic surgery division of Cipto Mangunkusumo Hospital, second-degree burns should be treated with SSD or antibiotic ointment [10]. However, prolonged usage of SSD can cause several side effects, including leukopenia, renal toxicity, an increasing resistance to the SSD cream, and delayed wound healing [10]. According to a study by Shahzad and Ahmed [11], some burn wounds treated by SSD cream resulted in incomplete wound healing, leaving contractures or hypertrophic scars. Although Aloe vera has the potential to heal wounds, over the years SSD has become the standard treatment. To help clarify this dilemma, we present an evidence-based case report in which we compared the effectiveness of Aloe vera versus SSD in healing second-degree burns. The effectiveness was measured according to the time needed for the burns to heal completely.

\section{Clinical scenario}

A 20-year-old woman came to our Emergency Department because of a burn on her right calf. She had been riding her motorcycle and was in an accident that trapped her right leg under the exhaust. She was admitted to the hospital $1 \mathrm{~h}$ after the accident. In the emergency room, her burn was cleaned using saline water, and she was prescribed an oral antibiotic. In addition, the burn was covered with antibiotic ointment (silver sulfadiazine). The patient and her family asked if they could use Aloe vera as an alternative treatment for the patient's burn.

\section{Clinical question}

In a patient with a second-degree burn, does treatment with Aloe vera produce better healing than silver sulfadiazine?

\section{MATERIALS AND METHODS}

To find relevant articles on this subject, we searched online databases (PubMed, Cochrane, Dynamed). The search queries are shown in table 1. Three keywords were used: second-degree burn, Aloe vera, silver sulfadiazine. Relevant articles found were then filtered based on inclusion and exclusion criteria. Inclusion criteria were studies in humans and English-language articles. We excluded review articles. The final articles, which were chosen by double filtering and abstract screening, were then appraised in terms of validity, importance, and applicability based on a checklist from www.cebm.net [12].

\section{RESULTS}

Altogether, 14 relevant articles were identified. After applying inclusion and exclusion criteria, eight specific articles were further screened. Finally, three articles were chosen. Fig. 1 shows the search flowchart containing the number of articles found and chosen. 
Table 1: Search queries from online databases

\begin{tabular}{|c|c|}
\hline Database & Search strategy \\
\hline PubMed & $\begin{array}{l}\text { \{(second [All Fields] AND degree [All Fields] AND ("burns" [MeSH Terms] OR "burns" [All Fields] OR "burn" [All Fields])\} AND } \\
\text { \{"aloe" [MeSH Terms] OR "aloe" [All Fields] OR ("aloe" [All Fields] AND "vera" [All Fields]) OR "aloe vera" [All Fields])\} AND } \\
\{(\text { "silver sulphadiazine" [All Fields] OR "silver sulfadiazine" [MeSH Terms] OR ("silver" [All Fields] AND "sulfadiazine" [All Fields]) } \\
\text { OR "silver sulfadiazine" [All Fields] }\}\end{array}$ \\
\hline Cochrane & "Second-degree burn"): ti,ab,kw AND ("Aloe vera"): ti,ab,kw AND ("silver sulfadiazine"): ti,ab,kw (word variations were searched) \\
\hline DYNAMED & Burns AND Aloe vera AND silver sulfadiazine \\
\hline
\end{tabular}

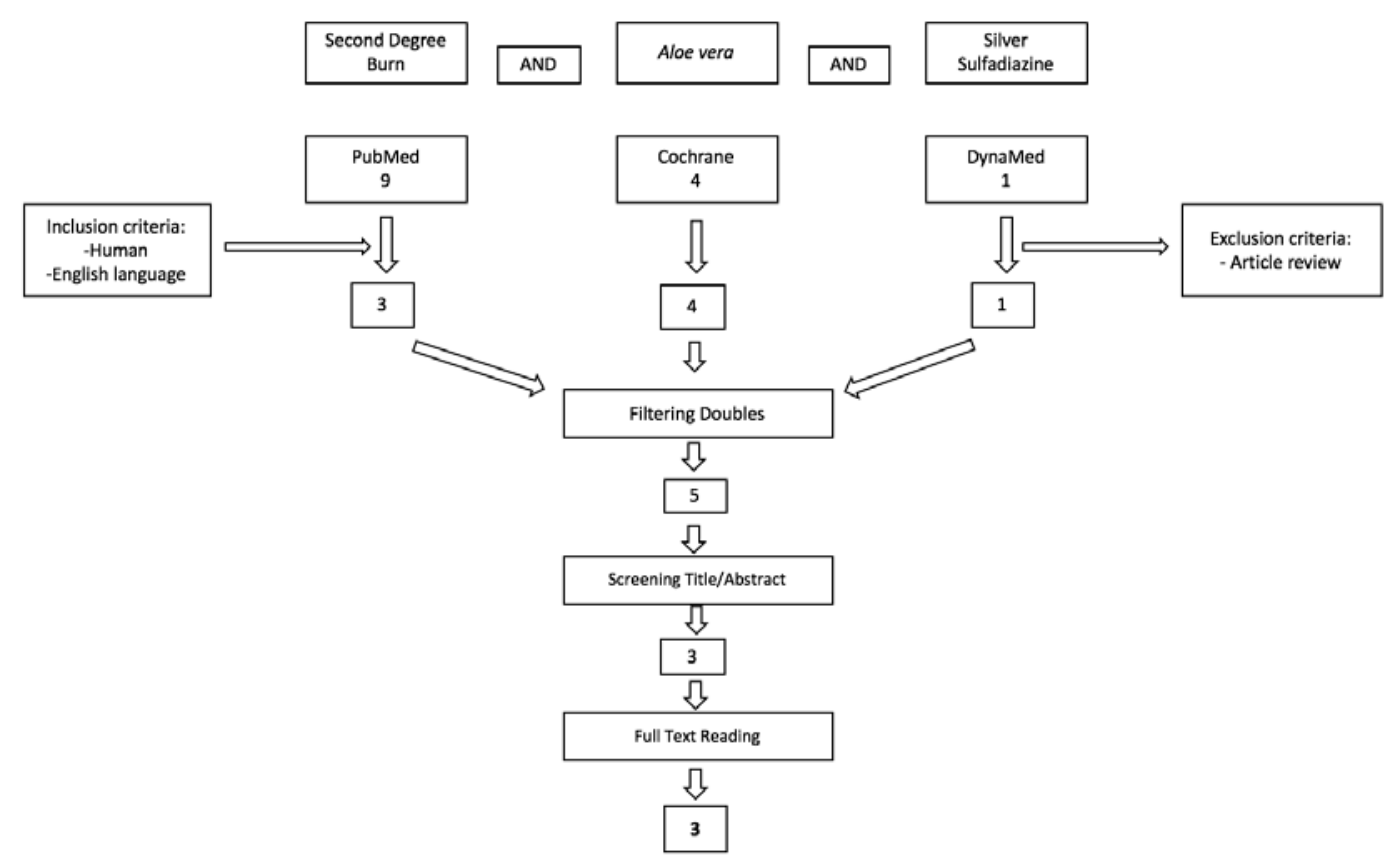

Fig. 1: Article search flowchart

The three randomized controlled trials chosen were those conducted by Khosarani et al. [13], Shahzad and Ahmed [11], and Panahi et al. [14]. Table 2 critiques those three articles in terms of validity, importance, and applicability. The study by Panahi et al. [14] is not included in table 2 because their Aloe vera formulation and assessment outcome were significantly different those of the other two selected studies.

Table 2: Critical appraisal

\begin{tabular}{|c|c|c|c|c|c|c|c|c|c|c|c|c|c|c|}
\hline & & & Validity & & & & Imp & rtan & & & Applicab & ity & & \\
\hline Article & $\begin{array}{l}\text { Stud } \\
\text { y } \\
\text { desi } \\
\text { gn }\end{array}$ & $\begin{array}{l}\text { Numb } \\
\text { er of } \\
\text { patien } \\
\text { ts }\end{array}$ & $\begin{array}{l}\text { Randomizat } \\
\text { ion }\end{array}$ & $\begin{array}{l}\text { Group } \\
\text { similar } \\
\text { ity }\end{array}$ & $\begin{array}{l}\text { Blindi } \\
\text { ng }\end{array}$ & $\begin{array}{l}\text { Equal } \\
\text { treatme } \\
\text { nt }\end{array}$ & RR & $\begin{array}{l}\mathbf{A R} \\
\mathbf{R}\end{array}$ & $\begin{array}{l}\mathbf{R R} \\
\mathbf{R}\end{array}$ & $\begin{array}{l}\text { NN } \\
\text { T }\end{array}$ & $\begin{array}{l}\text { Patient } \\
\text { differen } \\
\text { ce }\end{array}$ & $\begin{array}{l}\text { Feasib } \\
\text { le }\end{array}$ & $\begin{array}{l}\text { More } \\
\text { benefi } \\
\text { ts } \\
\text { than } \\
\text { harm }\end{array}$ & $\begin{array}{l}\text { Level } \\
\text { of } \\
\text { eviden } \\
\text { ce }\end{array}$ \\
\hline $\begin{array}{l}\text { Khoras } \\
\text { ani et } \\
\text { al. [13] }\end{array}$ & RCT & 30 & + & + & Double & + & 0 & 0.2 & 1 & 5 & + & + & + & $2 b$ \\
\hline $\begin{array}{l}\text { Shahza } \\
\text { d and } \\
\text { Ahmed } \\
{[11]}\end{array}$ & RCT & 50 & + & + & $\begin{array}{l}\text { Unclea } \\
\mathrm{r}\end{array}$ & + & $\begin{array}{l}0.1 \\
7\end{array}$ & 0.2 & $\begin{array}{l}0.8 \\
3\end{array}$ & 5 & - & + & + & $2 b$ \\
\hline
\end{tabular}

RCT: randomized controlled trial; RR: risk reduction; ARR: absolute risk reduction; NNT: number needed to treat.

Khorasani et al. [13] conducted their study in the Zare Burn Hospital in Iran as a randomized double-blinded controlled trial. It included 30 patients with two second-degree burn sites with $>40 \%$ of the total burn area included, totaling 60 burn sites. Each site was treated by SSD $1 \%$ cream or hand-made Aloe vera cream. The treatment continued until all the wounds were healed. Their study showed that in those treated by Aloe vera there was a faster re-epithelialization process, faster wound healing, and complete healing of burn wounds. Thus, the Aloe vera reduced the size of the burn wound area significantly faster than did SSD. In addition, all 30 of the sites treated with Aloe vera cream healed completely, whereas only 24 of the 30 sites treated with SSD were completely healed (the other six sites were left with burn scars).

Shahzad and Ahmed [11] conducted a similar randomized controlled trial study in Nishtar Hospital in Multan, Pakistan. In all, 50 patients who had been admitted to the plastic surgery department with $<25 \%$ second-degree burn wound areas were divided into two groups: 25 were treated with SSD 1\% cream and another 25 with AloeTone JelR consisting of $98 \%$ raw Aloe vera mucilage. Treatment continued 
until all wounds were healed. The results showed that Aloe vera gel healed the second-degree burn wounds better and alleviated pain faster than SSD 1\% cream. Among the 25 patients treated by Aloe vera gel, 24 healed completely, whereas only 19 of the 25 patients treated by SSD did so.

The third study was a randomized double-blinded clinical trial study conducted by Panahi et al. [14] in Iran. This study included 120 second-degree burn patients with a total burn area of $<50 \%$. The patients were divided into two groups of 60 each. The first group was treated by SSD $1 \%$ cream and the other with an herbal cream consisting of Aloe vera, Lavandula stoecha, and Pelargonium roseum, with the dosing at $5 \mathrm{~g}$ for every $10 \mathrm{~cm}^{2}$ of burn area once a day for $2 \mathrm{w}$. There were nine dropouts because of study protocol violation: four in the Aloe vera group and five in the SSD group. By the end of the study, 111 patients had completed the study, 55 in the SSD group and 56 in the herbal cream group. The results showed better pain alleviation with the herbal cream. The authors also assessed skin dryness, which exhibited no significant difference $(p>0.05)$ in the two study groups.

\section{DISCUSSION}

All three studies were RCTs. The studies by Khorasani et al. [13] and Panahi et al. [14] were conducted in Iran, whereas Shahzad and Ahmed [11] carried out their study in Pakistan. Each study has its advantages and limitations. Khorasani et al. [13] compared treatments by Aloe cream and SSD cream in the same patient but at different sites, thereby reducing possible bias. It also has an ample number of samples (sites). The authors, however, did not clarify their randomization method. They also concluded that the re-epithelialization process started faster with Aloe vera treatment, but this aspect was not explained in either the Results or Discussion sections. Shahzad and Ahmed [11] conducted randomized consecutive sampling, resulting in a random, statistically insignificant demographic distribution between the two treatment groups, which made the two groups similar. They also did not mention a blinding method. Their study, which took 2 y to complete, with the patients monitored closely in the hospital, had a rather small sample of only 50 patients. However, their detailed inclusion and exclusion criteria minimized bias. The double-blinded randomized control study by Panahi et al. [14] included more patients than the other two studies and used herbal cream consisting of three herbs-Aloe vera, Lavandula stoechas, and Pelargonium roseum-so the results might not fully represent the effectivity of Aloe vera. Compared with the first two studies, the assessment of their results differed in that it evaluated pain alleviation and skin dryness, which excluded it from the critical appraisal in table 2 . Nevertheless, the study is still valid based on the evidence of similarity in the treatment and control groups, comparable characteristics between the two groups, and its randomization design. It is also applicable for the patient in this case because of its feasibility and benefit outcomes. There were no further explanations about the cause of the patient withdrawals. They could have been due to the emergence of side effects, which was not mentioned in any of our three selected studies.

Based on the three studies, it seems that Aloe vera for treating second-degree burn wounds provides significantly better results than $1 \%$ SSD cream. However, all three studies were flawed because of poor methodology and incomplete data reporting. A systematic review by Dat et al. [15], which summarized studies of Aloe vera as treatment for acute or chronic wounds (e. g., surgical wounds, burns, laceration, ulcers, infected wounds), stated that all the RCT studies regarding Aloe vera effectivity had poor methodology, including the studies by Khorasani et al. [13] and Shahzad and Ahmed. [11]. Most of the studies were small, with only 30-100 patients. There was also a lack of consistency in the results among the studies. Schmidt and Greenspoon [8] stated that Aloe vera delayed wound healing after gynecological surgery, but the study was at a high risk of bias due to no blinding of the patients or the assessors. Dat et al. [15] also concluded that there was not enough high-quality clinical trial evidence available regarding the effectiveness of Aloe vera for healing wounds.

\section{CONCLUSION}

The clinical trials by Khorasani et al. [13], Shahzad and Ahmed [11], and Panahi et al. [14] stated that Aloe vera is more effective than SSD $1 \%$ cream for healing second-degree burn wounds. Therefore, Aloe vera treatment of second-degree burn wounds provided better results than SSD $1 \%$ cream, although high-quality evidence regarding its overall effectivity is still lacking.

\section{ACKNOWLEDGMENT}

We address our gratitude to Basic Herbal Medicine Elective Module for the opportunity to write this report. This article was presented at The 3rd International Conference and Exhibition on Indonesian Medical Education and Research Institute (ICE on IMERI 2018). We thank the $3^{\text {rd }}$ ICE on IMERI Committee who had supported the peer review and manuscript preparation before submitting to the journal.

\section{AUTHORS CONTRIBUTIONS}

All the author have contributed equally

\section{CONFLICT OF INTERESTS}

There are no conflicts of interest to declare

\section{REFERENCES}

1. Radha MH, Laxmipriya NP. Evaluation of biological properties and clinical effectiveness of Aloe vera: a systematic review. J Tradit Complement Med 2014;5:21-6.

2. Manvitha K, Bidya B. Aloe vera: a wonder plant: its history, cultivation and medicinal uses. J Pharmacogn Phytochem 2014;2:85-8.

3. Rajeswari R, Umadevi M, Sharmila Rahale C, Pushpa R, Selvavenkadesh S, Sampath Kumar KP, et al. Aloe vera: the miracle plant: its medicinal and traditional uses in India. J Pharmacogn Phytochem 2012;1:118-24.

4. Sahu PK, Giri DD, Singh R, Pandey P, Gupta S, Shrivastava AK, et al. Therapeutic and medicinal uses of aloe vera: a review. Pharmacol Pharm 2013;4:599-610.

5. Mitra R, Mitchell B, Gray C, Orbell J, Coulepis T, Muralitharan M. Medicinal plants of Indonesia. Asia Biotech 2007;11:726-8.

6. Christaki E, Florou Paneri P. Aloe vera: a plant for many uses. J Food Agric Environ 2010;8:245-9.

7. Akhoondinasab MR, Akhoondinasab M, Saberi M. Comparison of healing effect of aloe vera extract and silver sulfadiazine in burn injuries in experimental rat model. World J Plast Surg 2014;3:29-34.

8. Schmidt JM, Greenspoon JS. Aloe vera dermal wound gel is associated with a delay in wound healing. Obstet Gynecol 1991;78:115-7.

9. Hermans MH. Results of an internet survey on the treatment of partial thickness burns, full thickness burns, and donor sites. J Burn Care Res 2007;28:835-47.

10. Wardhana A. [Practical guidelines in Burn Wound Management.] (Indonesian) 1st ed. Jakarta: Lingkar Studi Bedah Plastik Foundation; 2014.

11. Shahzad MN, Ahmed N. Effectiveness of aloe vera gel compared with $1 \%$ silver sulphadiazine cream as burn wound dressing in second-degree burns. J Pak Med Assoc 2013;63:225-30.

12. Critical appraisal tools. CEBM; 2005. Available from: https://www.cebm.net/2014/06/critical-appraisal/ [Last accessed on 10 Oct 2018]

13. Khorasani G, Hosseinimehr S, Azadbakht M, Zamani A, Mahdavi MR. Aloe versus silver sulfadiazine creams for second-degree burns: a randomized controlled study. Surg Today 2009; 39:587-91.

14. Panahi $Y$, Beiraghdar F, Akbari H, Bekhradi H, Taghizadeh M, Sahebkar A. A herbal cream consisting of Aloe vera, Lavandula stoechas, and Pelargonium roseum as an alternative for silver sulfadiazine in burn management. Asian Biomed 2012;6:273-8.

15. Dat AD, Poon F, Pham KBT, Doust J. Aloe vera for treating acute and chronic wounds. Cochrane Database Syst Rev 2010;CD00876. 